\title{
IMPROVING POWER QUALITY IN MICROGRID BY MEANS OF USING POWER QUALITY CONDITIONER DEVICES
}

\author{
K.Ramya ${ }^{1}$, R.Prakash ${ }^{2}$ \\ ${ }^{1}$ Student, Power systems engineering, Vivekanandha College of engineering for women, India \\ ${ }^{2}$ Head and Professor of department of EEE, Vivekanandha College of engineering for women India
}

\begin{abstract}
The micro grids and the utility grid expose to their inner disturbance such as harmonics, unbalances and other power quality noises. To better isolate the device from their respective noises power quality conditioner is recommended between each micro grid and the utility grid. The cooperative control for enhance voltage harmonics and unbalances in micro grids is mentioned. The power quality enhancement of grid-interactive micro grids is discussed and explained. Power quality problem is reduced by means of using Unified Power Quality Conditioner (UPQC) in grid-connected micro grids is introduced in order to reduce harmonics in transmission and improve the power quality in distribution. Power quality problem includes voltage unbalances and harmonics. Interline Power Quality Conditioner (IPQC) is proposed to improve the power quality in multiline by reducing the harmonics and also unbalances of power in feeders by the process of synchronization. Finally, the coordinated control of harmonics and unbalances in micro grids is simulated by using MATLAB and the satisfactory results are obtained.
\end{abstract}

Keywords: - Harmonics, Inter line power quality conditioner. Microgrid, Synchronization, Transmission, Utility grid, Unified power quality conditioner

\section{INTRODUCTION}

The energy is neither be created nor destroyed but it can be converted from one form to another. The generation of an electrical energy is nothing but the conversion of various other forms of energy into an electrical energy. The electrical power is generated in bulk at the generating stations which are also called power stations. The generated electrical energy is demanded by the consumers. This causes due to power losses and power quality problems in the transmission lines FACTS device is introduced to reduce such problems. Microgrid leads to effective distribution in rural area all distribution includes effective power processor to control and monitor the power exchange between the grid. When such processor get fully exploited it leads to high power quality problems and power consumption by developing narrow band communication and local control algorithm full microgrid is exploited with marginal investment. A 48 pulse multilevel inverter was developed by cascading several units of three level diode clamped multilevel inverter with the help of phase shifting transformer. It leads to high cost and lengthy delays this cause serious deficiency in power transmission capacity while distribution [1].

Interline Power Flow Controller is one of the advanced controller in Flexible AC Transmission System controller it only compensates series and manages power flow in the system [2]. To simultaneously control the power flow two converter model $\mathrm{d}-\mathrm{q}$ orthogonal was introduced in the microgrid. By means of transmission angle variation series voltage is inject in the control region and the system gets over compensated [3]. Microgrid leads to effective distribution in rural area all distribution includes effective power in the control region processor to control and monitor the power exchange between the grids. When such processor get fully exploited it leads to high power quality problems and power consumption by developing narrow band communication and local control algorithm full microgrid is exploited with marginal investment and mainly microgrid can be able to disconnect from the microgrid loads from the disturbance and protects the transmission from harmonics. By grid interfacing converter system the conventional series and parallel structure is adapted. Two three phase four leg inverters is tend to construct grid interfacing system to compensate harmonic current it increases the complication and losses in the system [4]-[6]. Distributed generator not only inject power to the grid it also enhance power quality. By means of droop control technique it autonomously compensates voltage unbalances active and reactive droop control [7]. A flexible AC distribution system aims to improve the power quality and reliability in microgrid, the design of control algorithms and extended kalman filters is meant for frequency tracking and to extract harmonic in grid voltage and load current in microgrid. By minimizing the total system planning and operation cost and cost of load shedding co- optimization of power system is taken over to increase the economic and reliability of the grid. Microgrid has several distribution feeder and it can be 
distributed in multiple system it have number of buses, it also monitors the power quality in number of buses [8]-[11].

High frequency AC microgrid depends on utilization and common bus. Unified power quality conditioner based on $\mathrm{p}-\mathrm{q}$ theory it compensates reactive power and also current and voltage harmonics [12]. Due to high cost of UPQC minimum VA load is required here upqc combine with pso algorithm to analyze VA loading with optimization and without optimization is discussed [13]. Another method not only to compensate the reactive power a new converter has been designed consisting of power electronic devices that eliminates bulky power transformer and DC link capacitor that mitigates the power quality problems. In a broad overview of UPQC according to their connection single phase or three phase network was named in different types. Multiple installation of UPQC controller causes instability because of dynamic interaction [14]-[16]. Initially interphase power controller controls the power flow in the transmission line introducing unified controller can able to control power flow and fault current interruption. UPFC device can able to solve swing problems that may occur in bulky power system with long transmission line a new method is introduced called as state variable and using local measurement[17]-[18]. A microgrid is an electrical system that includes multiple loads and distributed energy resources that can operate in parallel with broader utility grid or as on electrical island. It is an autonomous grid whereas source and load are situated together. When the microgrid is connected along with the utility grid enormous amount of power is produced it leads to power quality problem such as harmonics. In order to reduce the power quality problems FACTS device is placed between the utility grid and the microgrid to improve the quality of power during distribution. FACTS deice plays very important role by means of reducing power quality problems. This paper is summarized as follows: In section 2 the operation of unified power quality conditioner to reduce harmonics are presented. In section 3 control of harmonics in multi lines by using interline power quality conditioner. Section 4 simulation result was discussed. Conclusion and future trends are pointed out in section 5.

\section{UNIFIED POWER QUALITY CONDITIONER}

The deep penetration of renewable energy sources leads to severe harmonics and voltage unbalances. Various international standards have included limitations of power quality to assure proper operation of micro grids. In the gridconnected operation, the utility needs to balance power flow between sources and loads, and to maintain voltage quality. In order to maintain decent power quality and collect more energy from RESs, power conditioning equipment is definitely required. Here, we will exclusively focus on cooperative solutions to voltage quality in the islanding micro grids, followed by the power quality conditioner devices to suppress voltage unbalances and harmonics in the grid-connected operation. Among the converter based FACTS-devices unified power flow quality Conditioner is a versatile FACTS-device, which can simultaneously control a local bus voltage and power flows

of a transmission line. The main disadvantage of this device is the high cost level due to the complex system setup.

UPQC is mainly used reduce the power quality problems in micro grid, which takes place when micro grid is connected with the utility grid enormous amount of power is produced between them and leads to voltage unbalances and harmonics. Here unified power quality conditioner is placed between the micro grid and utility grid.

The UPQC is the most versatile FACTS device with all capabilities voltage regulation, series compensation and phase shifting. It consists of two voltage source converter (VSC) coupled through a common de terminal.

a. One converter is connected in shunt with the line through a coupling transformer and is called as shunt converter.

b. Other converter is inserted in series with the transmission line and is named as series converter.

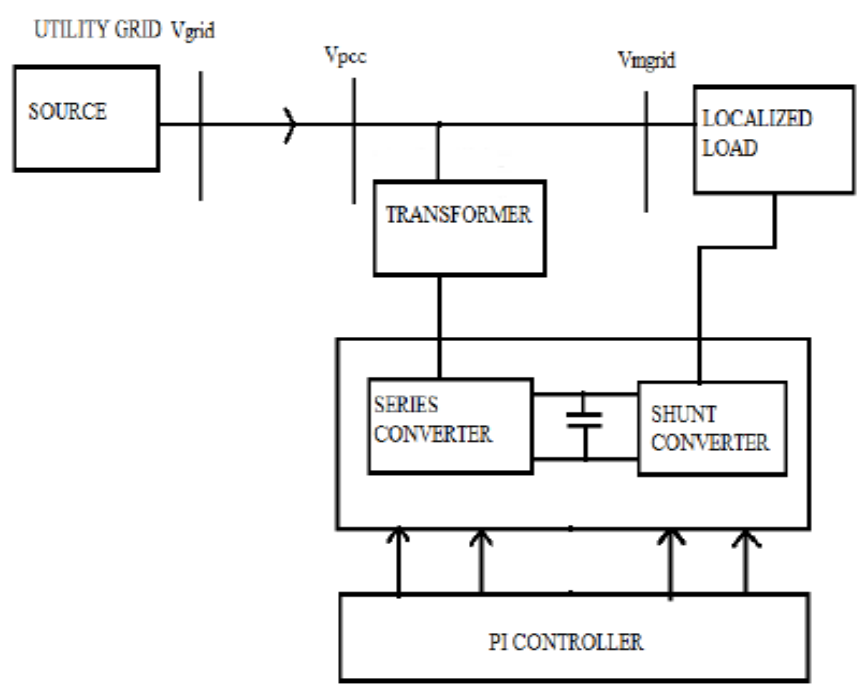

Fig 1: Block diagram of UPQC connected between grid and microgrid

The above block diagram shows about the UPQC device connected between the load and source were the power gets distributed to load by means of microgrid. Because of adjustable load connected with the grid power quality problem arises, by means of reducing power quality problems shunt and series converter in the UPQC device reduces such issues. PI controller is used to produce pulse to voltage source converter and also increases the speed of response.

The drawbacks of UPQC device are,

a. The only drawback of UPQC is to connect in each transmission line to improve the power quality during distribution of power to load. 
b. High cost because of connection UPQC device in each transmission line.

c. More transformers are used connecting along with device.

\subsection{Shunt Converter}

Shunt converter is used mainly to supply the real power demand of series converter. It maintains constant voltage of the DC bus. The net real power drawn from the AC system is equal to the losses of two converters and their coupling transformers. Shunt converter functions independently regulates the terminal voltage of inter connected bus by generating/absorbing amount of reactive power. Controlling shunt converter in voltage mode, so as to produce a well regulated voltage in micro grid. In this project shunt converter acts as a rectifier that receives AC voltage from load and converts to DC and stores in capacitor coupled across it.

\subsection{Series Converter}

The dc voltage for both converters is provided by common capacitor bank. The series converter is controlled to inject a voltage phasor in series with the line. Series converter exchanges both real and reactive power with the transmission line, reactive power is internally generated /absorbed by the series converter. Here series converter acts as an inverter that converts DC voltage in capacitor to $\mathrm{AC}$ and is fed into the transmission line.

PI controller is used to send gate pulse .Signal type of controller is used here that produce signal type of gate pulse. The error signal is received in the form of signal type compared with reference signal and gate pulse is produced.

\section{CONTROL OF HARMONICS IN MULTI LINE}

\section{BY USING IPQC}

IPQC is an advanced FACTS controller for power quality management in transmission system. By means of reducing cost, space and time conservation this device is chosen

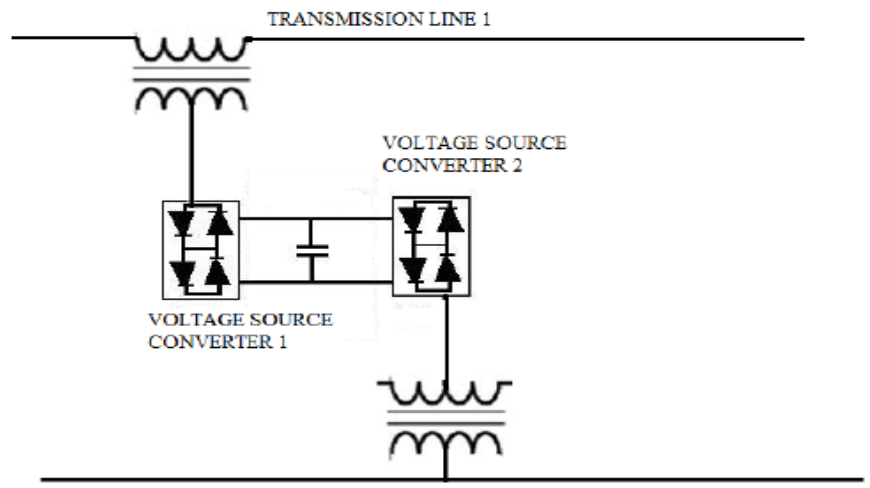

Fig 2: IPQC device
It can be able to monitor multi transmission line in a substation and also multiple systems. It is a more versatile device among the FACTS devices. Interline power quality conditioner (IPQC) is a new concept of FACTS controller for series compensation with the unique capability of power flow management among multiple line of a system. Voltage source converter is employed in the IPQC. A simple and typical test system model has been developed to check the performance of IPQC an advanced FACTS controller. It is common that, the IPQC employs a number of dc to ac inverters in order to offer series compensation for each line. As a new concept for the compensation and effective power flow management, it addresses the target of compensating a number of transmission lines at a given substation. The IPQC is a combination of two or more independently controllable SSSC which are solid-state voltage source converters. Construction of IPQC is same as that of unified power quality conditioner, has two voltage source converters.

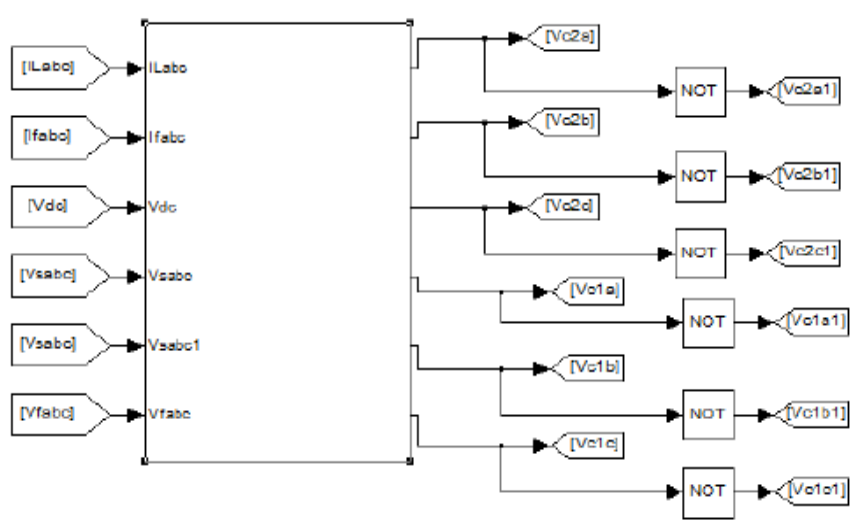

Fig 3: Measurement Block

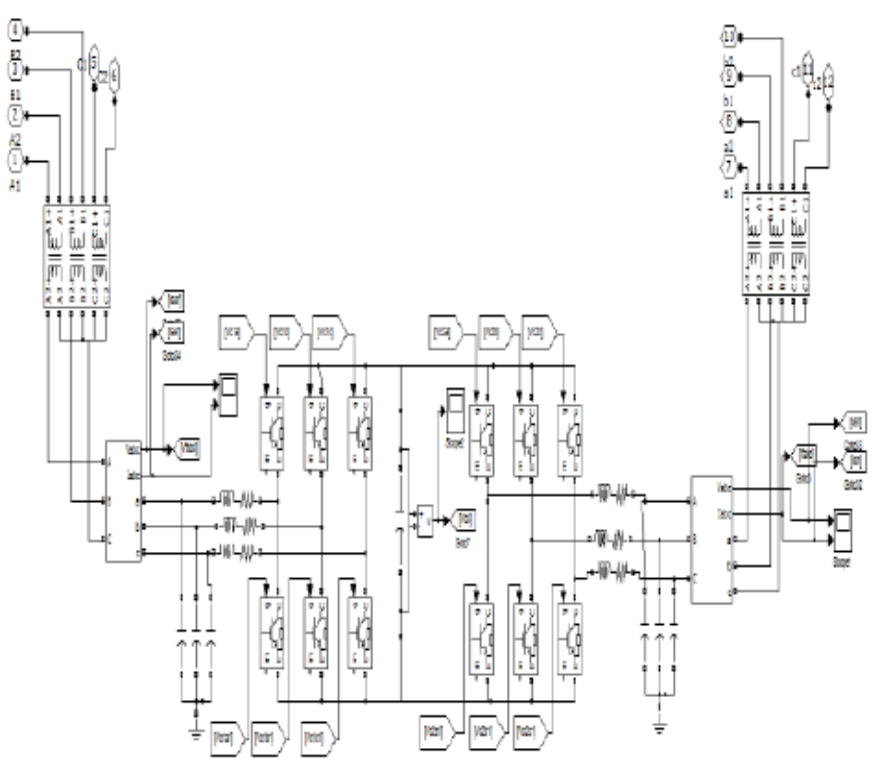

Fig 4: Design of IPQC 
Fig 4 shows that the construction of IPQC device. It is constructed by means of UPQC device, having twelve terminal transformers it can be connected to multilines with multiple systems. By means of multiple connection power quality problems can be reduced in multiple systems

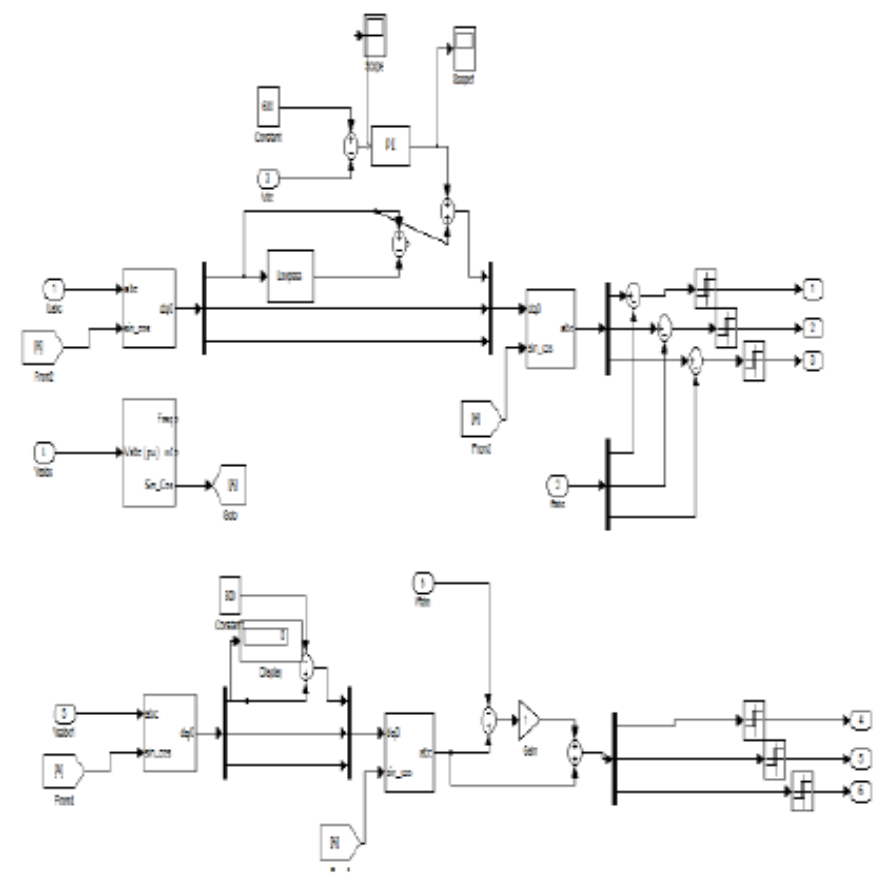

Fig 5: PI controller

From fig 5 shows PI controller in measurement block compensates the voltage in multiple systems and the controller is used to produce signal. PI controller is used as a feedback controller that can generate reference signal by means of comparing it with reference value 600 and it can be convert it to dqo transformation the wave is converted to $a b c$ transformation by means of parks transformation.

In this IPQC is designed with construction of UPQC device and measurement block. Twelve terminal transformers allowed acting UPQC device as IPQC. Simulation is designed along with measurement block constructed by means of PI controller that can reduce harmonics in multilines. Voltage is fed from the utility grid the twelve terminal transformers absorbs the voltage from the multiline voltage source transformer I acts as a rectifier that converts $\mathrm{AC}$ to $\mathrm{DC}$ and stores in the capacitor, voltage source transformer II absorbs voltage from the capacitor and it acts as a inverter that converters DC voltage to AC voltage this process is called synchronization process. By this process harmonic is reduced and improves the power quality in distribution. Synchronization is the process injecting harmonic voltage again into the transmission line that reaches the load without harmonics and improves the performance of the system.

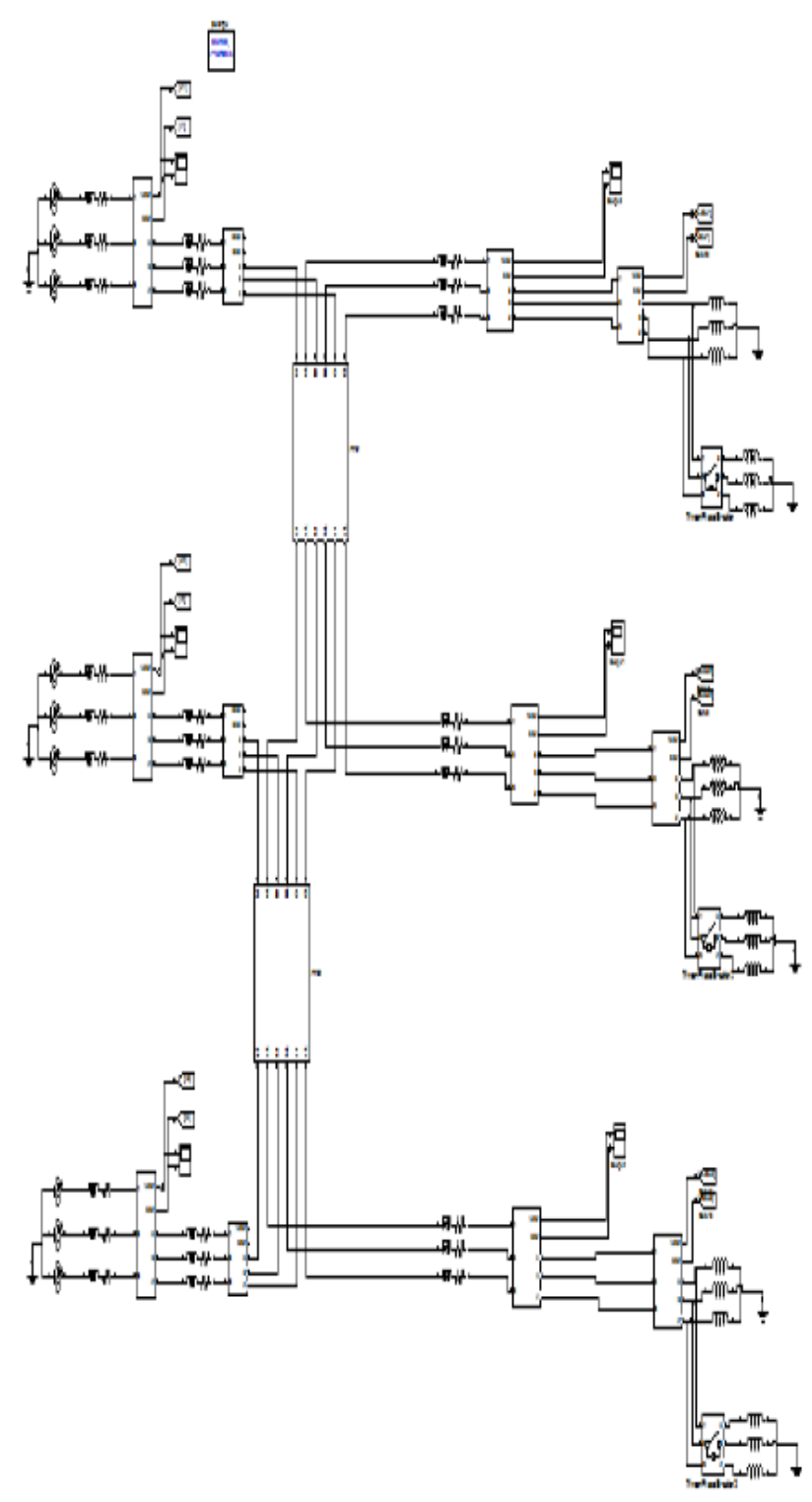

Fig 6: Simulation Diagram

\section{SIMULATION RESULTS AND DISCUSSION}

The below figures shows the simulation results, it describes about the performance of power distribution from the grid with Interline power quality conditioner device and without Interline power quality conditioner device. Without IPQC device the power flow will be subjected to some disturbance that reduces the amplitude of the waveform that decreases the power quality. By using IPQC device it reduces the disturbance in the power flow and increases the quality of power. Harmonics is produced due to adjustable load connected along with it. As mentioned above FACTS controller is used to rectify the disturbance in the power flow in the distribution side. 


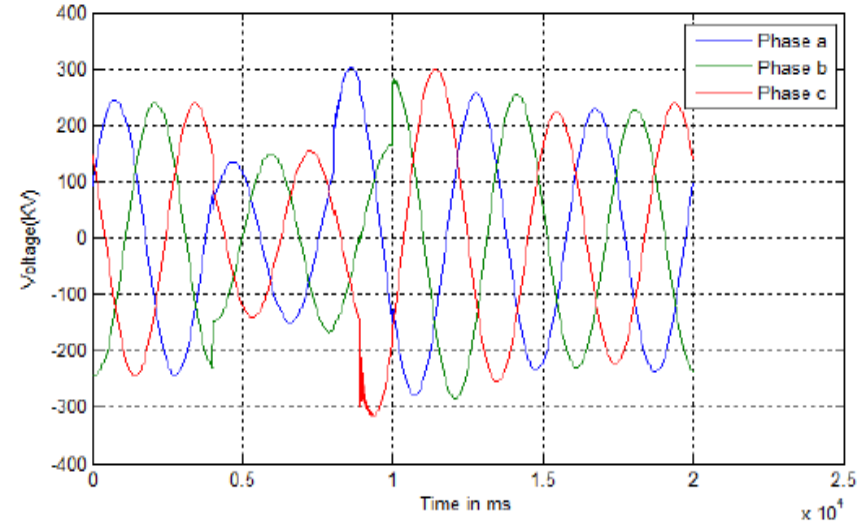

(a)

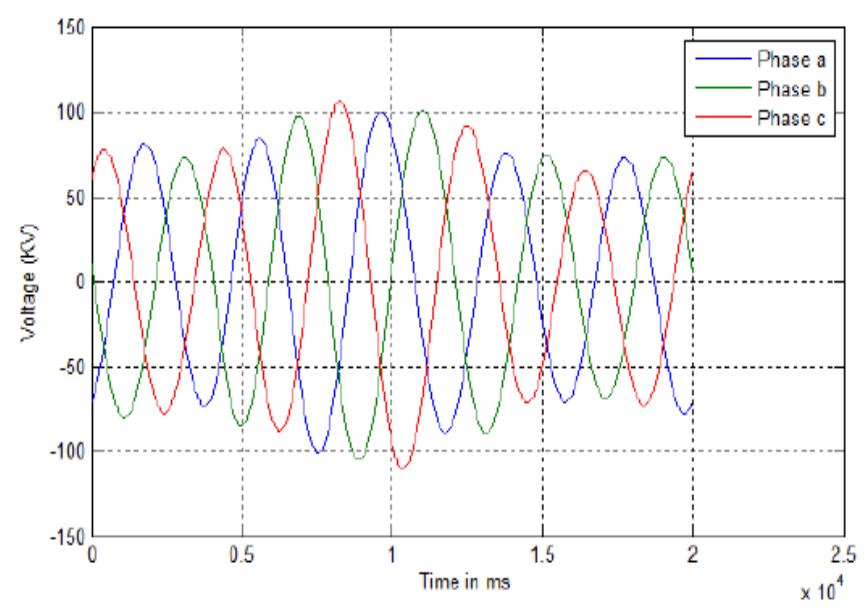

(b)

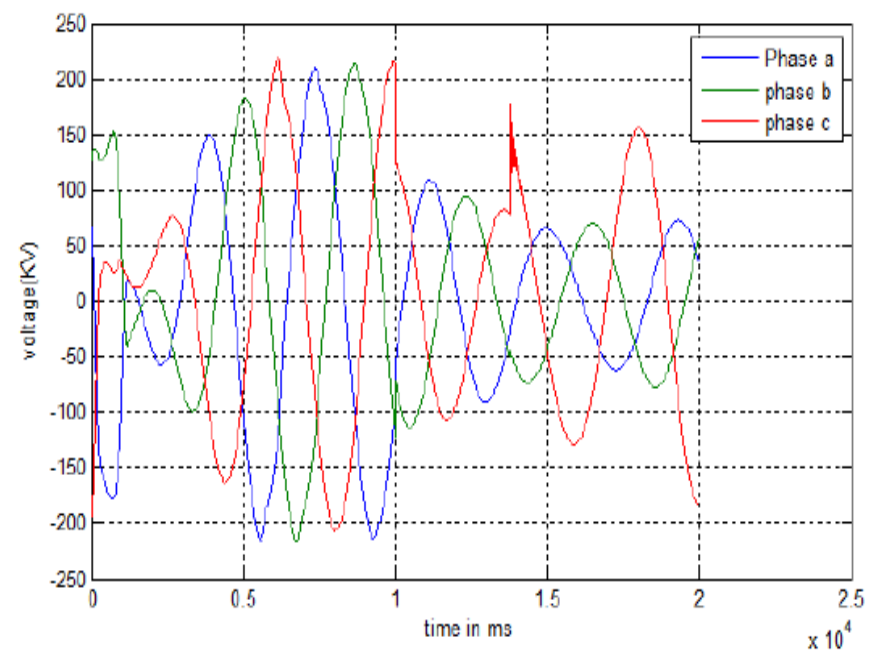

(c)

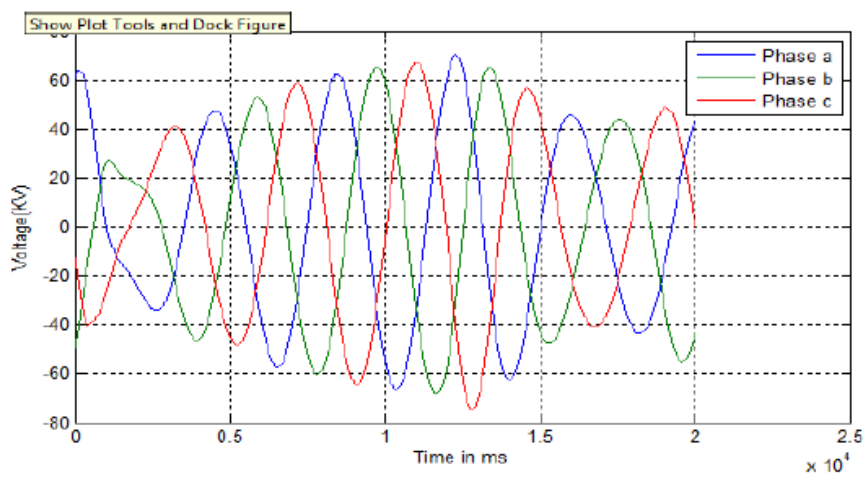

(d)

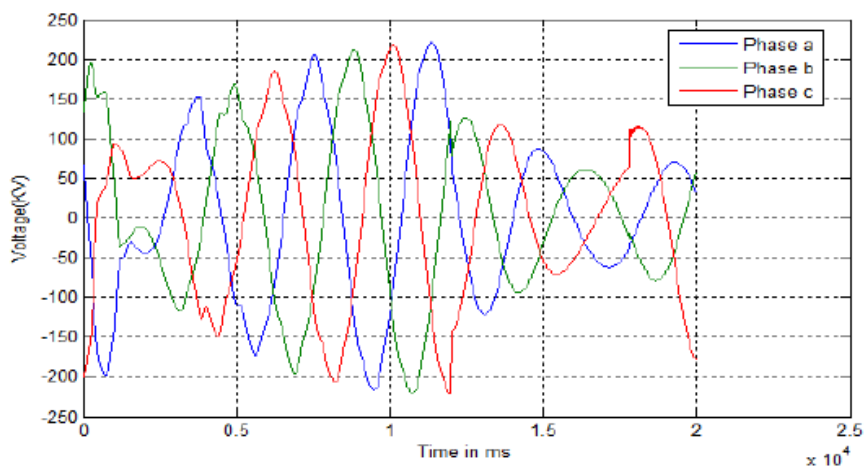

(e)

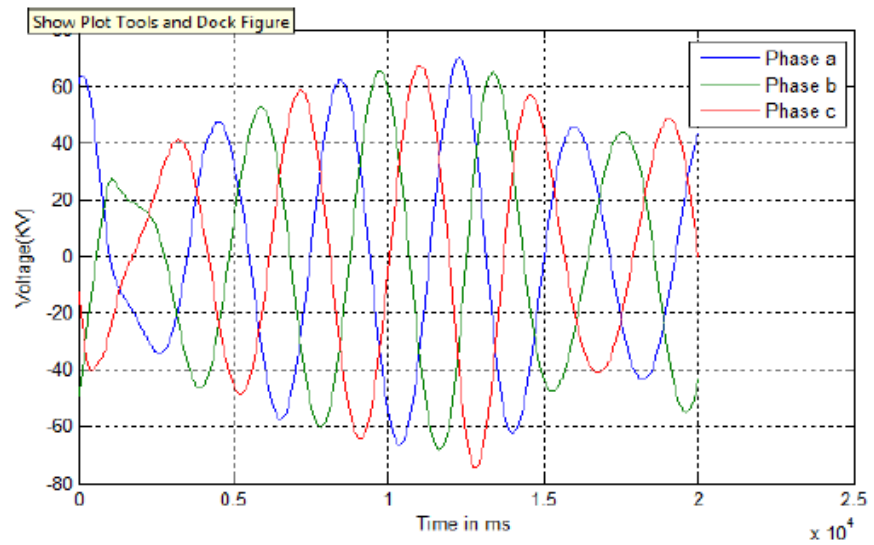

(f)

Fig 7: (a) Voltage waveform when adjustable load is started at the time interval 0.02 to 0.04 in system 1 without IPQC (b) Voltage waveform with IPQC in system 1 at the time interval 0.02 to 0.04 .(c) shows Voltage waveform when adjustable load is started at the time interval 0.04 to 0.06 in system 2 without IPQC (d)Voltage waveform with IPQC in system 2 at the time interval 0.04 to 0.06.(e) Voltage waveform when adjustable load is started at the time interval 0.06 to 0.08 in system 3 without IPQC (f) Voltage waveform without IPQC in system 3 at the time interval 0.06 to 0.08 
Fig 7(a) shows assume that the adjustable load is started at the time interval 0.02 to 0.04 . Voltage waveform is mentioned without IPQC in system 1. When the adjustable load is started at the particular time interval, the waveform at the particular interval has some disturbance fig 7(b) also shows voltage waveform with IPQC in system 1 at the time interval 0.02 to 0.04 . IPQC injects voltage from the load and rectifies the disturbance. Fig 7(c) Voltage waveform when adjustable load is started at the time interval 0.04 to 0.06 in system 2 without IPQC. When the adjustable load is started at the particular interval when drawing high current the waveform will subject to disturbance and the fig7(d) shows the voltage waveform with IPQC in system 2 at the time interval 0.04 to 0.06 . Fig 7 (e) voltage waveform when adjustable load is started at the time interval 0.06 to 0.08 in system 3 without IPQC Fig 7(f) shows voltage waveform without IPQC in system 3 at the time interval 0.06 to 0.08

\section{CONCLUSIONS}

In the simulation study, MATLAB Simulink environment is used to simulate the model of IPQC connected to a 3 phase system. The modeling of IPQC and analysis of power systems embedded with IPQC has been presented, which is capable of solving large power networks very reliably with the IPQC. The investigations related to the variation of control parameters and performance of the IPQC on power quality results are carried out. Simulation results show the effectiveness of IPQC to reduce the harmonics. IPQC system is proposed to reduce the power quality problem arising in multiline. Subsystems along with IPQC and measurement block are carried out. Voltage unbalances in multiline also reduced by means of measurement block.

\section{REFERENCES}

[1]. B. Muralimohan and M. Sudheerbabu "An Advanced FACTS Controller for Power Flow Management in Transmission System using IPFC" Research Journal of Applied Sciences, Engineering and Technology.

[2]. G. Irusapparajan and S. Rama Reddy "Experimental Results of Interline Power Flow Controller Systems" Research Journal of Applied Sciences, Engineering and Technology 3(7): 612-616, 2011

[3]. R.L. Vasquez-Arnez,F.A. MoreiraUFBA, Bahia, Brazil "Main advantages and limitations of the interline power flow controller: a steady-state analysis"

[4]. Paolo Tenti, Alessandro Costabeber,Paolo Mattavelli,and Daniela Trombetti "Distribution Loss Minimization by Token Ring Control of Power Electronic Interfaces in Residential Microgrids" IEEE transactions on industrial electronics, vol. 59, no. 10, october 2012

[5]. Robert H. Lasseter, Paolo Piagi University of WisconsinMadison "Microgrid: A Conceptual Solution" PESC'04 Aachen, Germany 20-25 June 2004

[6]. Fei Wang, Jorge L. Duarte, and Marcel A. M. Hendrix, "Grid-Interfacing Converter Systems With Enhanced Voltage
Quality for Microgrid Application-Concept and Implementation" IEEE transactions on power electronics, vol. 26, no. 12, december 2011

[7]. Mehdi Savaghebi, Alireza Jalilian, Juan C. Vasquez and Josep M. Guerrero, "Autonomous Voltage Unbalance Compensation in an Islanded Droop-Controlled Microgrid" IEEE transactions on industrial electronics, vol. 60, no. 4, april 2013

[8]. K. T. Tan, P. L. So,Y. C. Chu, and M. Z. Q. Chen, "A Flexible AC Distribution System Device for a Microgrid" IEEE transactions on energy conversion, vol. 28, no. 3, september 2013

[9]. Amin Khodaei and Mohammad Shahidehpour "MicrogridBased Co-Optimization of Generation and Transmission Planning in Power Systems" IEEE transactions on power systems, vol. 28, no. 2, may 2013

[10]. Qiang Fu, Luis F. Montoya, Ashish Solanki, AdelNasiri, Vijay Bhavaraju, T. Abdallah, and David C. Yu, "Microgrid Generation Capacity Design With Renewables and Energy Storage Addressing Power Quality and Surety" IEEE transactions on smart grid, vol. 3, no. 4, december 2012

[11]. Correa, J.M. ; Chakraborty, S. ; Simoes, M.G. ; Farret, F.A. "A single phase high frequency AC microgrid with an unified power quality conditioner" Industry Applications Conference, 2003. 38th IAS Annual Meeting. Conference Record of the Vol 2,2003

[12]. Kumar, G.S. ; Vardhana, P.H. ; Kumar, B.K. ; Mishra, M.K. "Minimization of VA loading of Unified Power Quality Conditioner (UPQC)” 10.1109/Powereng.2009.4915152

[13]. Kumar, G.S. ; Kumar, B.K. ; Kumar, M.M. “Optimal VA loading of UPQC during mitigation of unbalanced voltage sags with phase jumps in three-phase four-wire distribution system" Power System Technology (POWERCON), 2010 International Conference on Digital Object,2010

[14]. Mokhtarpour, A. ; Bathaee, M. ; Shayanfar, H.A. " Power quality compensation in smart grids with a single phase UPQC-DG" , 2nd Iranian Conference on smart grids (ICSG).2012

[15]. Khadkikar, V "Enhancing Electric Power Quality Using UPQC: A Comprehensive Overview" IEEE transactions on vol 27,2012

[16]. Q. Yu, L. Norum, T. Undeland, and S. Round, "Investigation of dynamic controllers for a unified power flow controller," in Proc. IEEE 22nd Int. Conf. Ind. Electron., Control Instrum., Taiwan, Aug. 1996, pp. 1764-1769

[17]. J. Pourhossein, G. B. Gharehpetian, and S. H. Fathi "Unified Interphase Power Controller (UIPC) Modeling and Its Comparison With IPC and UPFC" IEEE transactions on power delivery, vol. 27, no. 4, october 2012

[18]. Gholipour, E. ; Groupe de Recherche en Electrotechnique et Electronique de Nancy, France ; Saadate, S "Improving of transient stability of power systems using UPFC" 